OPEN ACCESS

Edited by:

Amanda W. Lund,

Oregon Health \& Science University,

United States

Reviewed by:

Traci Renae Lyons,

University of Colorado Anschutz Medical Campus, United States

Mihaela Skobe,

Icahn School of Medicine at Mount

Sinai, United States

*Correspondence:

Laure Garnier

laure.garnier@unige.ch

Stephanie Hugues stephanie.hugues@unige.ch

Specialty section:

This article was submitted to Immunological Tolerance and

Regulation,

a section of the journal

Frontiers in Immunology

Received: 19 December 2018 Accepted: 18 March 2019

Published: 09 April 2019

Citation:

Garnier L, Gkountidi A-O and Hugues S (2019) Tumor-Associated Lymphatic Vessel Features and Immunomodulatory Functions.

Front. Immunol. 10:720

doi: 10.3389/fimmu.2019.00720

\section{Tumor-Associated Lymphatic Vessel Features and Immunomodulatory Functions}

\author{
Laure Garnier*, Anastasia-Olga Gkountidi and Stephanie Hugues* \\ Department of Pathology and Immunology, Faculty of Medicine, University of Geneva, Geneva, Switzerland
}

The lymphatic system comprises a network of lymphoid tissues and vessels that drains the extracellular compartment of most tissues. During tumor development, lymphatic endothelial cells (LECs) substantially expand in response to VEGFR-3 engagement by VEGF-C produced in the tumor microenvironment, a process known as tumor-associated lymphangiogenesis. Lymphatic drainage from the tumor to the draining lymph nodes consequently increases, powering interstitial flow in the tumor stroma. The ability of a tumor to induce and activate lymphatic growth has been positively correlated with metastasis. Much effort has been made to identify genes responsible for tumor-associated lymphangiogenesis. Inhibition of lymphangiogenesis with soluble VEGFR-3 or with specific monoclonal antibodies decreases tumor spread to LNs in rodent models. Importantly, tumor-associated lymphatics do not only operate as tumor cell transporters but also play critical roles in anti-tumor immunity. Therefore, metastatic as well as primary tumor progression can be affected by manipulating tumor-associated lymphatic remodeling or function. Here, we review and discuss our current knowledge on the contribution of LECs immersed in the tumor microenvironment as immunoregulators, as well as a possible functional remodeling of LECs subsets depending on the organ microenvironment. Keywords: lymphatic vessels, anti-tumor immune response, metastasis, lymphangiogenesis, tumor
microenvironment

\section{INTRODUCTION}

Over the last few years, immunotherapy has evolved into a very promising new approach for fighting tumor progression. However, the proportion of cancer patients that positively respond to these treatments is still limited. Indeed, tumor cells foster mechanisms to escape immunosurveillance either by inducing poorly immunogenic tumors (immunoselection) or by setting up a tolerogenic environment that inhibits immune effector cells (immunosubversion) [reviewed in (1-3)]. Therefore, manipulations aiming at boosting anti-tumor immune cell responses and in particular tumor-specific $\mathrm{T}$ cell priming currently represent an extensive axis of investigations. 
During tumor development, lymphatic endothelial cells (LECs), the principal components of lymphatic vessels (LVs), undergo active modifications that facilitate metastatic dissemination, and induce immunoregulation. LEC phenotype and functions are strongly altered by inflammation or infections, which may directly influence on-going immune responses (4). In particular, it has been suggested that LECs immersed in the tumor microenvironment (TME) can act as immunoregulators of the anti-tumor $\mathrm{T}$ cell response (5). In vitro studies have further shown that, tumor derived LECs exhibit altered gene expression profiles compared to dermal derived LECs (6) and upregulate $\mathrm{PD}-\mathrm{L} 1$ to inhibit $\mathrm{T}$ cell activation $(7,8)$. On the other hand, a recent study has suggested that tumor-associated (TA) LVs might be beneficial for the efficacy of anti-PD-1 immunotherapy (9). Therefore, depending on the stage of tumor progression and on the immunological settings (immune evasion/immunosubversion or immunotherapy), LV might display positive and/or negative effects on tumor immunity. It is thus urgent to decipher precisely the roles for LVs in tumor cell dissemination and anti-tumor T cell immunity. In this review, we discuss the ability of LECs to shape tumor development through their contribution to tumor cell spreading and regulation of anti-tumoral $\mathrm{T}$ cell responses.

\section{LYMPHATIC VESSELS AS IMMUNOREGULATORS IN NON-TUMOR CONTEXT}

LVs develop as a hierarchical vasculature facilitating a unidirectional drainage system of fluid and cells from tissues toward draining lymph nodes (LNs) (10). They interlace the blood vessel circulation and play a crucial role in lipid absorption, tissue fluid homeostasis and immunity (11). The lymphatic system is a linear and blind-ended circuit. Initial lymphatic capillaries are composed of a single layer of LECs with minimal basement membrane and are not covered by pericytes or smooth muscle cells. This particular organization of LECs is highly permeable for the uptake of cells, macromolecules and interstitial fluids (12). Lymphatic capillaries drain to collecting lymphatics defined by pericyte and smooth muscle cell coverage, continuous basement membrane with "zipper-like" junctions, and a system of valves preventing retrograde flow $(12,13)$. Our knowledge of multiple LV functions has quickly evolved, based on the identification of LEC markers such as the transcription factor Prox-1 and the surface protein LYVE-1, that are not expressed by others endothelial cells. Prox-1 is primordial for the development and the maintenance of LECs (14-16). LYVE-1 is enriched in lymphatic junctions, highly expressed in initial lymphatics, but mostly absent from LV collectors [reviewed in (12)]. This molecule is implicated in dendritic cells (DCs) trafficking within LVs (17). LECs also express GP38 (podoplanin) and platelet endothelial cell adhesion molecule (PECAM-1 or CD31) that are markers shared with fibroblastic reticular cells (FRCs) and blood endothelial cells (BECs), respectively. An important function of lymphatics is to transport immune cells from peripheral tissues to LNs and therefore to participate to immune response initiation (18-21). Transcriptomic analysis of ex vivo LN stromal cell (LNSC) subsets in distinct immunological situations established that FRCs, BECs, and LECs express a multitude of immune mediators and growth factors that may influence the immune system. LNSCs are strongly modulated by inflammation or infections, and may contribute as active participants of on-going immune responses. In addition, a more precise characterization of these cells within distinct conditions suggested that LNSCs are specialized for their unique microenvironment (4). This might reflect a functional specialization of LNSC subsets depending on the organ microenvironment. Apart from their effect on tissue drainage and immune cell migration, LECs regulate $\mathrm{T}$ cell responses through different mechanisms (22). First, different studies in mice showed that steady-state LN LECs participate to peripheral $\mathrm{T}$ cell tolerance by presenting endogenously expressed tissue-restricted antigens $(17,18)$ through MHC class I (MHCI) molecules and eliminating autoreactive $\mathrm{CD}^{+} \mathrm{T}$ cells $(23-25)$. LN LECs can also cross-present exogenous antigens onto MHCI molecules, and further drive the apoptosis of antigen-specific $\mathrm{CD}^{+} \mathrm{T}$ cells (26). Whether LN LECs have an impact on peripheral $\mathrm{CD}^{+} \mathrm{T}$ cell responses in different immunological settings remains largely unknown and controversial. On the one hand, Rouhani et al. showed that LECs were unable to load MHC class II (MHCII) molecules with antigenic peptides due to their lack of H2-M expression at steady-state (27). However, LECs express the promoter IV (pIV) of CIITA, the master regulator for MHCII molecule expression (28). CIITA pIV being inducible by IFN- $\gamma$ (29), LECs might require exposure to IFN- $\gamma$ to upregulate $\mathrm{H}-2 \mathrm{M}$ molecules and be capable of MHCII-restricted antigen presentation. On the other hand, we published that surface MHCII expression on LNSCs results from the combination of both endogenous and acquired molecules. In vitro and in vivo, LNSCs further present peptide-MHCII complexes acquired from DCs to $\mathrm{CD} 4^{+} \mathrm{T}$ cells to induce their dysfunction. In particular, LECs specifically induce $\mathrm{CD} 4^{+} \mathrm{T}$ cell death, whereas LECs, BECs and FRCs all induce $\mathrm{T}$ cell anergy (28). Moreover, our recent studies demonstrate that the loss of MHCII expression on LNSCs in murine LNs impairs peripheral $\mathrm{CD}^{+} \mathrm{T}$ cell tolerance, and alters regulatory $\mathrm{T}$ cell populations, resulting in signs of spontaneous autoimmunity in elderly (30). Their lack of costimulatory molecules could explain LNSC implication in T cell tolerance. By releasing the sphingosine 1-phosphate (S1P), LECs play also an important role in the egress of activated $\mathrm{T}$ cells from LNs $(31,32)$. In addition, LEC-derived S1P is involved in naïve T cells survival, its signaling further providing sufficient energy to maintain their steady-state recirculation (33). LECs are also capable of preventing $\mathrm{T}$ cell activation and proliferation in a negative regulatory feedback process. Indeed, LECs from LNs produce nitric oxide in response to inflammatory signals (IFN- $\gamma$ and $\mathrm{TNF}$ ) produced by T cells, inhibiting back T cell activation (34). Finally, during inflammation, LECs present in collecting LV or in the skin suppress DC maturation via a Mac-1/ICAM-1 dependent mechanism (35), or through prostacyclin synthesis, respectively (36), leading to subsequent dampening of $\mathrm{T}$ cell activation. 


\section{TUMOR-ASSOCIATED LYMPHANGIOGENESIS AND METASTASIS}

The mortality linked to solid tumors is mainly associated with their capacity to disseminate to distant organs in a process known as metastasis (37). LVs are essential in tumor cell spreading as they function as "highways" connecting primary tumors to secondary lymphoid organs. The process of lymphatic proliferation, sprouting and enlargement during tumor progression, known as tumor lymphangiogenesis, and its implication in the spread of the disease has been studied for many years. TA-lymphangiogenesis correlates with metastasis and poor prognosis in several cancer types [as depicted in (10)], illustrating the relevance of lymphatic vasculature to cancer biology. A retrospective analysis of melanoma patients with lung metastases showed that high LV density and lymphatic invasion in metastatic regions were associated with poor prognosis (38). Moreover, LVs and immune cell infiltrates positively correlate in human metastatic cutaneous melanoma and colorectal cancer $(39,40)$. Therefore, therapies aiming at blocking tumor lymphangiogenesis are being considered as promising approaches for the treatment of such malignancies [as discussed in (41)]. Importantly, several inhibitors targeting distinct actors of lymphangiogenesis have been developed in murine tumor models and could be translated into clinic to reduce metastasis. Accordingly, the inhibition of the prolymphangiogenic VEGFR3 signaling by using VEGFR-3 blocking antibodies or VEGF-C/D trap reduces LN, and/or distant organ metastasis in different tumor mouse models (42-45). Conversely, overexpression of two lymphangiogenic factors VEGF-C and VEGF-D increases metastasis dissemination to sentinel LNs (46-49). In particular, molecules or antibodies blocking VEGF-C/VEGFR3 signaling have been tested in clinical trials, some have gone one to be approved for cancer treatment $(10,50)$ [as reviewed in (10)]. However, although blockade of VEGFR3 has no noticeable effect on established lymphatics, VEGF-C signaling has been described to promote homeostasis of intestinal and brain meningeal LVs $(51,52)$. Therefore, it would be crucial to develop treatment that specifically target pro-tumorigenic LEC functions in order to exclude any potential intestinal or neurological side effect.

In mice, LECs from tumors present a distinct molecular profile compared to dermal LECs. Altered pathways include chemokines, extracellular matrix, cell adhesion, and inflammatory responses (6). These observations reflect significant levels of LEC plasticity that is highly regulated by the tissue microenvironment.

\section{Pro-Lymphangiogenic Factors and Tumor Cell Spreading}

The TME is composed of cancer cells, the extracellular matrix (ECM), stromal cells, and various immune cell types, impacting both tumor cell development and anti-tumor immunity. All these cells produce many factors that lead to the establishment of an intratumoral environment characterized by chronic inflammation, immunosuppression, angiogenesis, and lymphangiogenesis, the latter being the focus of this review (Figure 1.1).

The proliferation, migration and survival of LECs depend mainly on VEGFR2/3 signaling axis, which is driven by VEGF$\mathrm{C}$ and VEGF-D (Vascular Endothelial Growth Factors -C and -D) $(53,54)$ produced by many different cell types, including tumor cells and immune cells. VEGF-C and VEGF-D, considered to be major drivers of tumor lymphangiogenesis, are associated with LN and/or distant organ metastasis (38, 46-48, 55-57) (Figure 1.1). Using orthotopic spontaneous metastasis models in nude mice, it has been shown that VEGF-C expression by tumor cells favors metastatic propagation in distal organs (57). Moreover, a recent study indicated that, in a transgenic mouse model with increased lymphangiogenesis in the lung, TALVs contribute to the dissemination of metastases to distant organs (38). In vitro studies have deciphered the molecular mechanisms implicated in the activation of VEGF-C/D signaling pathway. Following VEGFR-3 engagement, the protein kinase $\mathrm{C}$ is activated, leading to the phosphorylation of AKT, and subsequent LEC migration, survival and proliferation (53). Neuropilin 2 (Nrp-2), an additional receptor for VEGF-C, is also expressed by LECs, and contributes to lymphatic sprouting $(58,59)$.

In several human cancer, VEGF-C and COX-2 (cyclooxygenase 2 , an enzyme implicated in prostaglandin pathway) expression are associated with LV density and LN metastasis (6063). Interestingly, preclinical and clinical trials using different Non-Steroidal Anti-Inflammatory Drugs (NSAIDs), blocking COX-2 and subsequent prostaglandin production, have reported a decrease in cancer incidence, tumor cell dissemination, and finally global cancer morbidity. These observations suggest that NSAIDs could be applied for the treatment of metastasis (64-66). In mice, beside a direct effect on LECs, VEGF-C/D increases the levels of prostaglandins in the TME, further promoting TA-lymphangiogenesis. VEGF-D indeed inhibits the enzyme 15-hydroxyprostaglandin dehydrogenase (15-PGDH), therefore enhancing LEC exposure to prostaglandins in collecting lymphatic vessels (67). The engagement of EP3 signaling (prostaglandin E2 receptor 3) on tumor-associated stromal cells promotes lymphangiogenesis (68). Moreover, increased amounts of prostaglandins amplify the production of VEGF-C by tumor and immune cells, contributing to lymphangiogenesis and tumor cell dissemination $(62,63)$.

TNF- $\alpha$ interaction with its TNF receptor 1 (TNFR-1) triggers VEGF-C secretion by tumor-associated macrophages (TAM), amplifying LV expansion and metastasis (69). On the other hand, TNF- $\alpha$ signaling in LECs directly favors their proliferation and their migration, without however being sufficient to constitute a fully competent lymphatic network (69). Indeed, TNF- $\alpha$ induced lymphangiogenesis completely depends on the VEGF-C/VEGFR3-induced LEC tip formation. Similarly, VEGFC/VEGFR3-induced LEC tip formation is required to trigger fibroblast growth factor (FGF2) induced lymphangiogenesis and foster tumor metastasis in mice (70). In contrast, proangiogenic factors such as platelet derived growth factor B (PDGFBB) (71) and angiopoietins (ANGPTs) (72) can act as direct lymphaniogenic factors by binding, respectively, PDGF-BB 


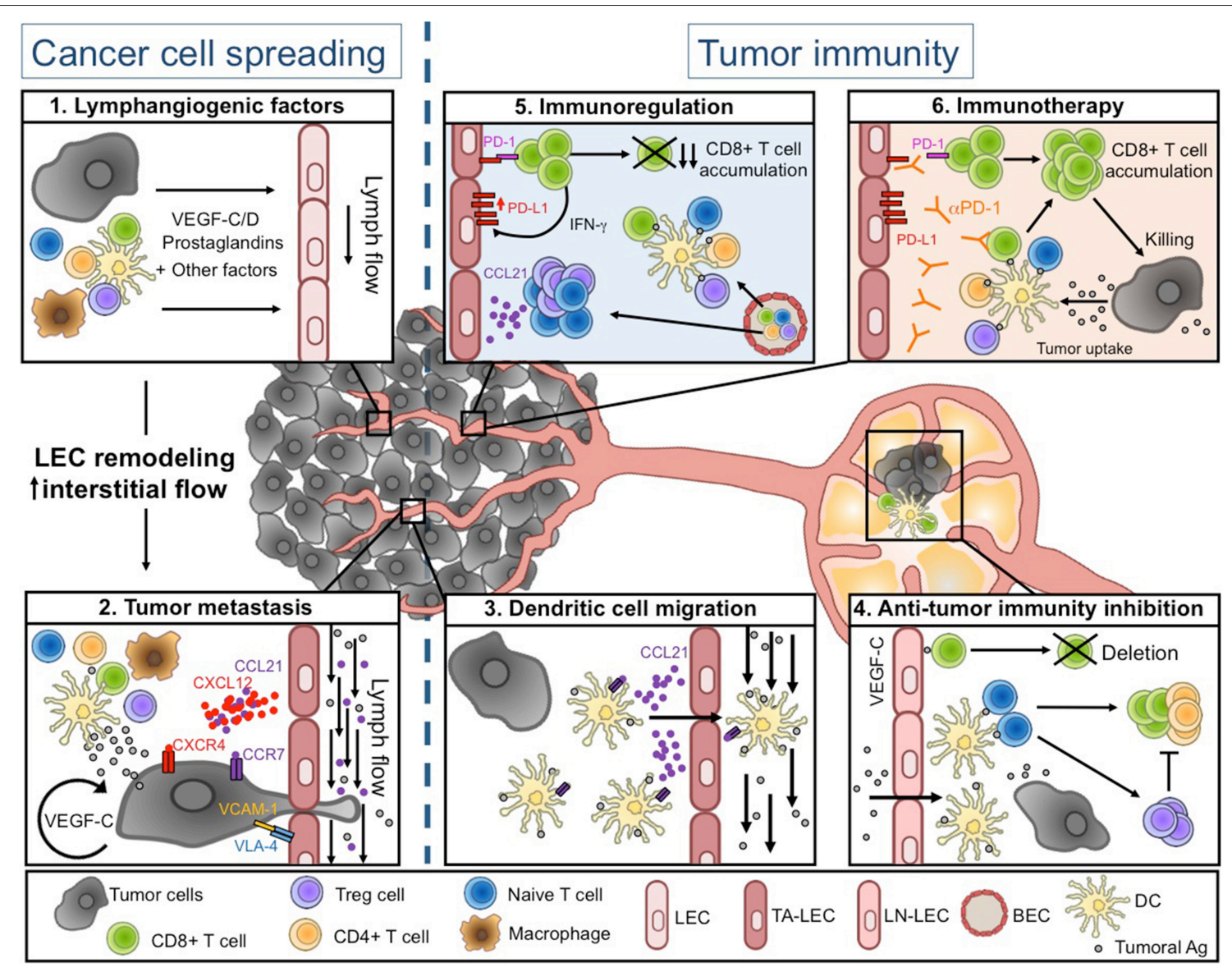

FIGURE 1 | Lymphatic vessel functions during tumor progression. (Left) Tumor-associated lymphatics facilitate tumor cell spreading. Soluble factors produced in the tumor microenvironment (TME) induce LEC remodeling and interstitial flow increase (1), resulting in enhanced tumor cell migration into lymphatic vessels (LVs) (2). (Right) Tumor-associated lymphatics regulate anti-tumor immunity. Tumor associated (TA-) LECs actively promote DC migration toward draining lymph nodes (LNs) (3). DCs further present tumor-antigens to naïve T cells, leading to initiation of adaptive anti-tumor immunity. In tumor-draining LNs, VEGF-C exposed LEC

cross-present tumor-antigens (Ags) and induce the deletion of anti-tumor CD8 ${ }^{+} \mathrm{T}$ cells (4). Intratumorally, naïve and activated T cells are weakly restimulated by local DCs, due to the immunosuppressive TME. The TME favors in particular the infiltration of Treg and naiive T cells through a CCL21-dependent pathway. TA-LECs also express high levels of PD-L1 in response to IFN- $\gamma$ produced by effector T cells (5). Upon anti-PD-1 immunotherapy, TA-LEC mediated immunosuppression might be abrogated, contributing to enhanced T cell activation and tumor cell elimination (6). Drawing designed by Rémi Jeandenand.

receptors and receptors Tie1/2 expressed by LECs. Whether TGF$\beta$ enhances $(73,74)$ or inhibits $(75)$ lymphangiogenesis depends on tumor models, rendering difficult the targeting of this cytokine for the regulation of LEC remodeling in tumors.

\section{Mechanism of Metastasis Dissemination}

Emerging evidence suggest that lymphatic vessels undergo several changes in response to lymphangiogenic factors during the course of metastasis. In addition to promoting tumoral cell transportation, LVs deliver lymphangiogenic factors produced by the primary tumor to condition sentinel LNs prior to the arrival and seeding of cancer cells $(56,76-78)$. In the mouse B16F10 melanoma model, LVs from distant metastatic regions, such as LNs and lungs, attract chemoresistant $\mathrm{CD} 133^{+} \mathrm{CXCR} 4^{+}$ melanoma cells by secreting CXCL12 (79).

TA-LVs were for long described as passive conduits for tumoral cell spread toward sentinel LNs and distant organs. However, several studies highlighted that the tumor microenvironment actively modifies LV features of primary tumor and draining LNs to further promote metastasis. VEGF-C acts in an autocrine manner to improve metastasis dissemination by favoring proteolytic activity and motility of tumor cells (80). Besides its direct effect on tumoral cells, VEGF-C modulates the expression of integrins and chemokines by LECs to facilitate tumor invasiveness. The integrin $\alpha 4 \beta 1$ (or VLA-4), which is considered as a marker of activated and proliferating LECs in human and murine tumors (81), is activated by the VEGF$\mathrm{C} / \mathrm{PI} 3 \mathrm{~K} \alpha$ pathway in LECs to promote lymphangiogenesis and tumor metastasis in LNs. Therefore, the blockade or the genetic deletion of this integrin on LVs prevents LEC migration and invasion, and inhibits VCAM-1 mediated adhesion of tumoral cell to LECs (82). The secretion of CCL21 by LECs, which drives CCR7-dependent tumor migration through LVs, is also enhanced in response to VEGF-C (80). Moreover, 
CCL21-dependent recruitment of innate lymphoid cells results in the production of CXCL13 by tumoral stromal cells, which in turn induces metastasis through RANK/RANKL signaling (83). Transmural flow modulates LEC function by promoting the expression of CCL21 and by downregulating VE-cadherin and PECAM-1, two adhesion molecules crucial for cellular junctions (84). Modification of interstitial flow influences CCR7 ligand secretion by tumoral cells, providing an autologous chemotactic gradient (85). In human, CCR7 expression by tumor cells is associated with LN metastasis in several cancers (86-88) (Figure 1.2).

CCL1 secretion by LECs located in the subcapsular sinuses of LNs is crucial to control tumor cell invasion into LNs. Indeed, blocking the CCL1 receptor (CCR8) inhibits metastasis by preventing tumor cell egress from collecting lymphatics into LNs without affecting their entry into intratumoral lymphatics (89). Recently, the screening of 810 mutant mouse strains allowed the identification of 23 genes that, when disrupted, alter the establishment of metastatic foci (90). Notably, they demonstrated that the deletion of the sphingosine-1-phosphate transporter SPNS2 in LECs decreases pulmonary metastasis and promotes effector $\mathrm{T}$ cell and natural killer cell infiltration in lungs (90).

Recently, Black et al., have shown that the prolymphangiogenic factor COX-2 enhances the expression of semaphorin $7 \mathrm{a}$ (sema7a) in breast tumoral cells. This leads in turn to the activation of $\beta 1$-integrin receptors on adjacent tumoral cells and LECs, to finally increase lymphangiogenesis and cancer cell dissemination (91). Moreover, sema7a induces gp38 upregulation by tumor-infiltrating macrophages, therefore promoting their adhesion to LVs and consequently boosting lymphangiogenesis and metastasis in breast cancer (92). In agreement, Sema7a gene expression is observed in a high frequency in human breast cancer and correlates with metastasis and poor prognosis (91).

Apart from their implication in metastasis dissemination, accumulating studies indicate that LECs modulate anti-tumor immunity. The roles of LECs in tumor spreading and antitumoral immune responses are discussed below.

\section{DUAL ROLE OF TUMOR-ASSOCIATED LYMPHATIC VESSELS IN ANTI-TUMOR IMMUNITY}

Growing evidence highlight that, in addition to acting as drains for soluble factors and tumoral cell transport, TA-LVs further play important roles in shaping antitumor immunity. Therefore, the modulation of lymphangiogenesis could impact not only metastasis dissemination but also anti-tumor immunity and primary tumor growth. In the context of solid tumors, lymph flow from tumors is increased, driving intense interstitial flow in the tumor stroma, and enhancing lymphatic drainage to the draining LNs (93). TA-LVs are primarily required for the recruitment of immune cells and adaptive immune response initiation $(39,94)$. However, immunosuppressive features of LECs in TME will subsequently dampen ongoing anti-tumor immunity (5). Therefore, LVs play a dual role on tumor immunity that might be temporally regulated. Finally, immunotherapy approaches can be potentialized by TA-lymphangiogenesis in melanoma tumors (9), further highlighting the relevance of modulating LV functions during tumor development.

\section{Lymphatic Vessels Are Necessary for the Initiation of Anti-Tumoral Responses}

$\mathrm{T}$ cell activation and infiltration in tumors are key steps of antitumor immunity. Indeed, while Treg infiltration is associated with a poor outcome in patients, intratumoral cytotoxic $\mathrm{T}$ lymphocytes are beneficial for clinical outcome $(95,96)$. Although some studies have suggested that naïve $\mathrm{T}$ cell could infiltrate tumors and be locally activated (97-99), antigen transport by dendritic cells (DCs) through LVs toward draining LNs is nevertheless crucial for the initiation of tumorspecific T cell responses, at least in melanomas $(39,100)$. Indeed, tumor drainage, DC trafficking and subsequent induction of antitumor adaptive immune responses are drastically impaired in transgenic mice lacking or with disturbed local LVs $(39,94)$. Upon inflammation, LECs in afferent LVs produce CCL21 that is necessary to DC egress from the tissue toward lymphatics (101, 102). Moreover, the expression of CLEC-2 by DCs is essential for their migration into LNs. The activation of CLEC-2 by GP38, which is highly expressed by LECs and FRCs, induces actin polymerization and motility of DCs (103). In a tumoral context, CCR7 expression by DCs is primordial for their migration into tumor draining LNs and subsequent $\mathrm{T}$ cell activation (100) (Figure 1.3).

In agreement with a role for lymphatic vasculature in the initiation of anti-tumor immunity, lymphatic vessel density (LVD) or lymphatic gene expression in primary tumors of colorectal or melanomas patients positively correlates with inflammation and immune cell infiltration $(9,39,40,104)$.

\section{Lymphatic Vessels Suppress Effector T Cells During Tumor Progression}

The lymphangiogenic factor VEGF-C produced in the tumor favors immunological tolerance in murine melanoma, including the induction of tumor-specific $\mathrm{CD}^{+} \mathrm{T}$ cell deletion (5) (Figure 1.4) $(5,26)$. This is consistent with studies in human melanoma, where active CTLs can be found in the circulation, while they exhibit an exhausted phenotype when localized in tumors (105). In addition, LECs in tumor draining LNs cross-present tumor antigens through MHCI complexes, and further drove the apoptosis of tumor-specific $\mathrm{CD}^{+} \mathrm{T}$ cells. The expression of the immunosuppressive molecule PD-L1 is enhanced at the surface of LECs after antigen specific interaction with $\mathrm{CD} 8^{+} \mathrm{T}$ cells in vitro $(7,26)$. Moreover, blockade of PD-L1 on antigen pulsed immortalized LECs in vitro increases $\mathrm{CD}^{+}$ $\mathrm{T}$ cell activation (7). In vivo, in several tumor mouse models, TA-LECs express higher levels of PD-L1 compared to naïve skin LECs $(7,8)$, the highest PD-L1 expression being observed in immunogenic tumors (8). Recently, Lane et al. demonstrated that PD-L1 expression by non-hematopoietic cells prevents $\mathrm{CD} 8^{+} \mathrm{T}$ 
cells accumulation in melanoma. IFN- $\gamma$ production by antigenspecific $\mathrm{CD}^{+} \mathrm{T}$ cells is primarily necessary to induce PDL1 expression on LECs. Using mice with LECs deficient for IFN- $\gamma$ receptor, they established that the specific loss of IFN$\gamma$ sensitivity in LVs improves $\mathrm{CD}^{+} \mathrm{T}$ cell-dependent control of melanoma tumor growth and mouse survival (8). Thus, during tumor development, a negative feedback loop is set up between LECs and T cells. LECs up-regulate PD-L1 expression in response to IFN- $\gamma$ produced by tumor specific $\mathrm{CD} 8^{+} \mathrm{T}$ cells, and subsequently inhibit $\mathrm{T}$ cell accumulation in tumors (Figure 1.5).

In human metastatic melanoma, VEGF-C expression positively correlates with $\mathrm{T}$ cell infiltration and CCL21 expression (9). CCL21 plays a crucial role in the establishment of a tolerogenic tumor microenvironment by recruiting CCR7 ${ }^{+}$ regulatory $\mathrm{T}$ cells in primary tumors and by promoting the formation of lymphoid like stromal structures with immunosuppressive features (106). CCL21 further attracts naïve $\mathrm{T}$ cells that can be locally activated in response to immune blockade or vaccination (9).

\section{CONCLUDING REMARKS}

Recent studies indicate that tumor-associated LECs significantly contribute to shaping the immunosuppressive TME, therefore helping tumors hijack the immune system from an efficient to an incompetent anti-tumor response. Altogether, several observations highlight a new role for lymphatics in promoting tumor development, suggesting that lymphatic endothelium in the local microenvironment may be a novel target for immunomodulation. In agreement with these hypotheses, a recent publication demonstrated that following exposure to tumor derived factors, FRCs of the tumor draining LNs undergo multiple changes to convert into a immunosuppressive phenotype, such as decreased production of IL-7 and CCL19/21 (107). Whether a similar profound reprogramming occurs to LECs in tumor draining LNs remains to be determined.

\section{REFERENCES}

1. Zitvogel L, Tesniere A, Kroemer G. Cancer despite immunosurveillance: immunoselection and immunosubversion. Nat Rev Immunol. (2006) 6:71527. doi: $10.1038 /$ nri1936

2. Motz GT, Coukos G. Deciphering and reversing tumor immune suppression. Immunity. (2013) 39:61-73. doi: 10.1016/j.immuni.2013.07.005

3. Chen DS, Mellman I. Oncology meets immunology: the cancer-immunity cycle. Immunity. (2013) 39:1-10. doi: 10.1016/j.immuni.2013.07.012

4. Malhotra D, Fletcher AL, Astarita J, Lukacs-Kornek V, Tayalia P, Gonzalez SF, et al. Transcriptional profiling of stroma from inflamed and resting lymph nodes defines immunological hallmarks. Nat Immunol. (2012) 13:499-510. doi: $10.1038 /$ ni.2262

5. Lund AW, Duraes FV, Hirosue S, Raghavan VR, Nembrini C, Thomas SN, et al. VEGF-C promotes immune tolerance in B16 melanomas and crosspresentation of tumor antigen by lymph node lymphatics. Cell Rep. (2012) 1:191-9. doi: 10.1016/j.celrep.2012.01.005

6. Clasper S, Royston D, Baban D, Cao Y, Ewers S, Butz S, et al. A novel gene expression profile in lymphatics associated with tumor growth and nodal metastasis. Cancer Res. (2008) 68:7293-303. doi: 10.1158/0008-5472.CAN-07-6506
Whereas, VEGFC driven TA-lymphangiogenesis correlates with increased intratumoral inflammation (39) and immune suppression in progressing tumors (5), it seems also to be necessary for the response of the tumor microenvironment to immunotherapeutic intervention, as demonstrated for PD1 blocking antibodies (9) (Figure 1.6). This suggests that TALECs potentiate immunotherapy by attracting naive $\mathrm{T}$ cells through a CCL21 dependent mechanism. Accordingly, LVs and immune cell infiltrates positively correlated in metastatic cutaneous melanoma and colorectal cancer patients $(39,40)$. Once in the tumor, naive $\mathrm{T}$ cells can be locally primed upon PD-1 blockade, which reverts the immunosuppressive $\mathrm{T}$ cell imprinting and induces long-lasting anti-tumor immunity. Therefore, it is tempting to speculate that LV density in tumors could be used as a predictor for positive response to immune checkpoint blockade. Additional research will determine how to selectively target LEC immunosuppressive functions in tumors, which could, combined to immunotherapeutic approaches, lead to the conversion of a "cold" into "hot" immunogenic TME and potentiate anti-tumor $\mathrm{T}$ cell responses.

\section{AUTHOR CONTRIBUTIONS}

LG, A-OG, and SH wrote the manuscript. LG conceptualized Figure 1.

\section{FUNDING}

SH's laboratory is supported by the Swiss National Science Foundation (310030_166541), the Swiss Cancer League, the Leenaards Foundation, and Carigest SA.

\section{ACKNOWLEDGMENTS}

We thank Rémi Jeandenand for the design of the drawing (Figure 1).

7. Dieterich LC, Ikenberg K, Cetintas T, Kapaklikaya K, Hutmacher C, Detmar M. Tumor-associated lymphatic vessels upregulate PDL1 to inhibit T-cell activation. Front Immunol. (2017) 8:66. doi: 10.3389/fimmu.2017.00066

8. Lane RS, Femel J, Breazeale AP, Loo CP, Thibault G, Kaempf A, et al. IFNgamma-activated dermal lymphatic vessels inhibit cytotoxic $T$ cells in melanoma and inflamed skin. J Exp Med. (2018) 215:3057-74. doi: $10.1084 /$ jem.20180654

9. Fankhauser M, M.Broggi AS, Potin L, Bordry N, Jeanbart L, Lund AW, et al. Tumor lymphangiogenesis promotes $\mathrm{T}$ cell infiltration and potentiates immunotherapy in melanoma. Sci Transl Med. (2017) 9:eaal4712. doi: 10.1126/scitranslmed.aal4712

10. Stacker SA, Williams SP, Karnezis T, Shayan R, Fox SB, Achen MG. Lymphangiogenesis and lymphatic vessel remodelling in cancer. Nature reviews. Cancer. (2014) 14:159-72. doi: 10.1038/nrc3677

11. Zheng W, Aspelund A, Alitalo K. Lymphangiogenic factors, mechanisms, and applications. J Clin Invest. (2014) 124:878-87. doi: 10.1172/JCI71603

12. Alitalo K, Tammela T, Petrova TV. Lymphangiogenesis in development and human disease. Nature. (2005) 438:946-53. doi: 10.1038/nature04480

13. Baluk P, Fuxe J, Hashizume H, Romano T, Lashnits E, Butz S, et al. Functionally specialized junctions between endothelial cells of lymphatic vessels. J Exp Med. (2007) 204:2349-62. doi: 10.1084/jem.20062596 
14. Wigle JT, Harvey N, Detmar M, Lagutina I, Grosveld G, Gunn MD, et al. An essential role for Proxl in the induction of the lymphatic endothelial cell phenotype. EMBO J. (2002) 21:1505-13. doi: 10.1093/emboj/21.7.1505

15. Wigle JT, Oliver G. Proxl function is required for the development of the murine lymphatic system. Cell. (1999) 98:769-78. doi: 10.1016/S0092-8674(00)81511-1

16. Johnson NC, Dillard ME, Baluk P, McDonald DM, Harvey NL, Frase SL, et al. Lymphatic endothelial cell identity is reversible and its maintenance requires Prox1 activity. Genes Dev. (2008) 22:3282-91. doi: 10.1101/gad.1727208

17. Johnson LA, Banerji S, Lawrance W, Gileadi U, Prota G, Holder KA, et al. Dendritic cells enter lymph vessels by hyaluronan-mediated docking to the endothelial receptor LYVE-1. Nat Immunol. (2017) 18:762-70. doi: $10.1038 /$ ni. 3750

18. Olszewski WL. The innate reaction of the human skin lymphatic system to foreign and self-antigens. Lymphat Res Biol. (2005) 3:50-7. doi: 10.1089/lrb.2005.3.50

19. Pugh CW, MacPherson GG, Steer HW. Characterization of nonlymphoid cells derived from rat peripheral lymph. J Exp Med. (1983) 157:1758-79. doi: 10.1084/jem.157.6.1758

20. Mackay CR, Marston WL, Dudler L. Naive and memory T cells show distinct pathways of lymphocyte recirculation. J Exp Med. (1990) 171:801-17. doi: 10.1084/jem.171.3.801

21. Randolph GJ, Angeli V, Swartz MA. Dendritic-cell trafficking to lymph nodes through lymphatic vessels. Nat Rev Immunol. (2005) 5:617-28. doi: 10.1038/nri1670

22. Card CM, Yu SS, Swartz MA. Emerging roles of lymphatic endothelium in regulating adaptive immunity. J Clin Invest. (2014) 124:943-52. doi: 10.1172/JCI73316

23. Cohen JN, Guidi CJ, Tewalt EF, Qiao H, Rouhani SJ, Ruddell A, et al. Lymph node-resident lymphatic endothelial cells mediate peripheral tolerance via Aire-independent direct antigen presentation. J Exp Med. (2010) 207:681-8. doi: 10.1084/jem.20092465

24. Fletcher AL, Lukacs-Kornek V, Reynoso ED, Pinner SE, Bellemare-Pelletier A, Curry MS, et al. Lymph node fibroblastic reticular cells directly present peripheral tissue antigen under steady-state and inflammatory conditions. $J$ Exp Med. (2010) 207:689-97. doi: 10.1084/jem.20092642

25. Tewalt EF, Cohen JN, Rouhani SJ, Guidi CJ, Qiao H, Fahl SP, et al. Lymphatic endothelial cells induce tolerance via PD-L1 and lack of costimulation leading to high-level PD-1 expression on CD8 T cells. Blood. (2012) 120:4772-82. doi: 10.1182/blood-2012-04-427013

26. Hirosue S, Vokali E, Raghavan VR, Rincon-Restrepo M, Lund AW, Corthesy-Henrioud $\mathrm{P}$, et al. Steady-state antigen scavenging, crosspresentation, and $\mathrm{CD}^{+} \mathrm{T}$ cell priming: a new role for lymphatic endothelial cells. J Immunol. (2014) 192:5002-11. doi: 10.4049/jimmunol.13 02492

27. Rouhani SJ, Eccles JD, Riccardi P, Peske JD, Tewalt EF, Cohen JN, et al. Roles of lymphatic endothelial cells expressing peripheral tissue antigens in CD4 T-cell tolerance induction. Nat Commun. (2015) 6:6771. doi: $10.1038 /$ ncomms7771

28. Dubrot J, Duraes FV, Potin L, Capotosti F, Brighouse D, Suter T, et al. Lymph node stromal cells acquire peptide-MHCII complexes from dendritic cells and induce antigen-specific CD4(+) T cell tolerance. J Exp Med. (2014) 211:1153-66. doi: 10.1084/jem.20132000

29. Reith W, LeibundGut-Landmann S, Waldburger JM. Regulation of MHC class II gene expression by the class II transactivator. Nature reviews. Immunology. (2005) 5:793-806. doi: 10.1038/nri1708

30. Dubrot J, Duraes FV, Harle G, Schlaeppi A, Brighouse D, Madelon $\mathrm{N}$, et al. Absence of MHC-II expression by lymph node stromal cells results in autoimmunity. Life Sci Alliance. (2018) 1:e201800164. doi: $10.26508 /$ lsa.201800164

31. Grigorova IL, Schwab SR, Phan TG, Pham TH, Okada T, Cyster JG. Cortical sinus probing, S1P1-dependent entry and flow-based capture of egressing $\mathrm{T}$ cells. Nat Immunol. (2009) 10:58-65. doi: 10.1038/ni.1682

32. Pham TH, Baluk P, Xu Y, Grigorova I, Bankovich AJ, Pappu R, et al. Lymphatic endothelial cell sphingosine kinase activity is required for lymphocyte egress and lymphatic patterning. J Exp Med. (2010) 207:17-27. doi: 10.1084/jem.20091619
33. Mendoza A, Fang V, Chen C, Serasinghe M, Verma A, Muller J, et al. Lymphatic endothelial S1P promotes mitochondrial function and survival in naive T cells. Nature. (2017) 546:158-61. doi: 10.1038/nature22352

34. Lukacs-Kornek V, Malhotra D, Fletcher AL, Acton SE, Elpek KG, Tayalia P, et al. Regulated release of nitric oxide by nonhematopoietic stroma controls expansion of the activated T cell pool in lymph nodes. Nat Immunol. (2011) 12:1096-104. doi: 10.1038/ni.2112

35. Podgrabinska S, Kamalu O, Mayer L, Shimaoka M, Snoeck H, Randolph GJ, et al. Inflamed lymphatic endothelium suppresses dendritic cell maturation and function via Mac-1/ICAM-1-dependent mechanism. J Immunol. (2009) 183:1767-79. doi: 10.4049/jimmunol.0802167

36. Christiansen AJ, Dieterich LC, Ohs I, Bachmann SB, Bianchi R, Proulx ST, et al. Lymphatic endothelial cells attenuate inflammation via suppression of dendritic cell maturation. Oncotarget. (2016) 7:39421-35. doi: 10.18632/oncotarget.9820

37. Liotta LA. Cancer cell invasion and metastasis. Sci Am. (1992) 266:54-9:62-3.

38. Ma Q, Dieterich LC, Ikenberg K, Bachmann SB, Mangana J, Proulx ST, et al. Unexpected contribution of lymphatic vessels to promotion of distant metastatic tumor spread. Sci Adv. (2018) 4:eaat4758. doi: 10.1126/sciadv.aat4758

39. Lund AW, Wagner M, Fankhauser M, Steinskog ES, Broggi MA, Spranger S, et al. Lymphatic vessels regulate immune microenvironments in human and murine melanoma. J Clin Invest. (2016) 126:3389-402. doi: 10.1172/JCI79434

40. Mlecnik B, Bindea G, Kirilovsky A, Angell HK, Obenauf AC, Tosolini $\mathrm{M}$, et al. The tumor microenvironment and Immunoscore are critical determinants of dissemination to distant metastasis. Sci Transl Med. (2016) 8:327ra26. doi: 10.1126/scitranslmed.aad6352

41. Dieterich LC, Detmar M. Tumor lymphangiogenesis and new drug development. Adv Drug Delivery Rev. (2016) 99:148-60. doi: 10.1016/j.addr.2015.12.011

42. Gogineni A, Caunt M, Crow A, Lee CV, Fuh G, van Bruggen N, et al. Inhibition of VEGF-C modulates distal lymphatic remodeling and secondary metastasis. PLoS ONE. (2013) 8:e68755. doi: 10.1371/journal.pone.0068755

43. Burton JB, Priceman SJ, Sung JL, Brakenhielm E, An DS, Pytowski B, et al. Suppression of prostate cancer nodal and systemic metastasis by blockade of the lymphangiogenic axis. Cancer Res. (2008) 68:7828-37. doi: 10.1158/0008-5472.CAN-08-1488

44. Lin J, Lalani AS, Harding TC, Gonzalez M, Wu WW, Luan B, et al. Inhibition of lymphogenous metastasis using adeno-associated virus-mediated gene transfer of a soluble VEGFR-3 decoy receptor. Cancer Res. (2005) 65:6901-9. doi: 10.1158/0008-5472.CAN-05-0408

45. Roberts N, Kloos B, Cassella M, Podgrabinska S, Persaud K, Wu $\mathrm{Y}$, et al. Inhibition of VEGFR-3 activation with the antagonistic antibody more potently suppresses lymph node and distant metastases than inactivation of VEGFR-2. Cancer Res. (2006) 66:2650-7. doi: 10.1158/0008-5472.CAN-05-1843

46. Stacker SA, Caesar C, Baldwin ME, Thornton GE, Williams RA, Prevo $\mathrm{R}$, et al. VEGF-D promotes the metastatic spread of tumor cells via the lymphatics. Nat Med. (2001) 7:186-91. doi: 10.1038/84635

47. Skobe M, Hawighorst T, Jackson DG, Prevo R, Janes L, Velasco P, et al. Induction of tumor lymphangiogenesis by VEGF-C promotes breast cancer metastasis. Nat Med. (2001) 7:192-8. doi: 10.1038/84643

48. Mandriota SJ, Jussila L, Jeltsch M, Compagni A, Baetens D, Prevo R, et al. Vascular endothelial growth factor-C-mediated lymphangiogenesis promotes tumour metastasis. EMBO J. (2001) 20:672-82. doi: $10.1093 /$ emboj/20.4.672

49. Hoshida T, Isaka N, Hagendoorn J, di Tomaso E, Chen YL, Pytowski B, et al. Imaging steps of lymphatic metastasis reveals that vascular endothelial growth factor- $\mathrm{C}$ increases metastasis by increasing delivery of cancer cells to lymph nodes: therapeutic implications. Cancer Res. (2006) 66:8065-75. doi: 10.1158/0008-5472.CAN-06-1392

50. Saif MW, Knost JA, Chiorean EG, Kambhampati SR, Yu D, Pytowski B, et al. Phase 1 study of the anti-vascular endothelial growth factor receptor 3 monoclonal antibody LY3022856/IMC-3C5 in patients with advanced and refractory solid tumors and advanced colorectal cancer. Cancer Chemother Pharmacol. (2016) 78:815-24. doi: 10.1007/s00280-016-3134-3 
51. Antila S, Karaman S, Nurmi H, Airavaara M, Voutilainen MH, Mathivet T, et al. Development and plasticity of meningeal lymphatic vessels. J Exp Med. (2017) 214:3645-67. doi: 10.1084/jem.20170391

52. Nurmi H, Saharinen $P$, Zarkada G, Zheng W, Robciuc MR, Alitalo K. VEGF-C is required for intestinal lymphatic vessel maintenance and lipid absorption. EMBO Mol Med. (2015) 7:1418-25. doi: 10.15252/emmm.201505731

53. Makinen T, Veikkola T, Mustjoki S, Karpanen T, Catimel B, Nice EC, et al. Isolated lymphatic endothelial cells transduce growth, survival and migratory signals via the VEGF-C/D receptor VEGFR-3. EMBO J. (2001) 20:4762-73. doi: 10.1093/emboj/20.17.4762

54. Veikkola T, Jussila L, Makinen T, Karpanen T, Jeltsch M, Petrova TV, et al. Signalling via vascular endothelial growth factor receptor-3 is sufficient for lymphangiogenesis in transgenic mice. EMBO J. (2001) 20:1223-31. doi: 10.1093/emboj/20.6.1223

55. Tammela T, Alitalo K. Lymphangiogenesis: molecular mechanisms and future promise. Cell. (2010) 140:460-76. doi: 10.1016/j.cell.2010.01.045

56. Hirakawa S, Brown LF, Kodama S, Paavonen K, Alitalo K, Detmar M. VEGF-C-induced lymphangiogenesis in sentinel lymph nodes promotes tumor metastasis to distant sites. Blood. (2007) 109:1010-7. doi: 10.1182/blood-2006-05-021758

57. Das S, Ladell DS, Podgrabinska S, Ponomarev V, Nagi C, Fallon JT, et al. Vascular endothelial growth factor-C induces lymphangitic carcinomatosis, an extremely aggressive form of lung metastases. Cancer Res. (2010) 70:181424. doi: 10.1158/0008-5472.CAN-09-3675

58. Bagri A, Tessier-Lavigne M, Watts RJ. Neuropilins in tumor biology. Clin Cancer Res. (2009) 15:1860-4. doi: 10.1158/1078-0432.CCR-08-0563

59. Xu Y, Yuan L, Mak J, Pardanaud L, Caunt M, Kasman I, et al. Neuropilin2 mediates VEGF-C-induced lymphatic sprouting together with VEGFR3. J Cell Biol. (2010) 188:115-30. doi: 10.1083/jcb.200903137

60. Siironen P, Ristimaki A, Narko K, Nordling S, Louhimo J, Andersson S, et al. VEGF-C and COX-2 expression in papillary thyroid cancer. Endocr Relat Cancer. (2006) 13:465-73. doi: 10.1677/erc.1.01114

61. Lyons TR, Borges VF, Betts CB, Guo Q, Kapoor P, Martinson HA, et al. Cyclooxygenase-2-dependent lymphangiogenesis promotes nodal metastasis of postpartum breast cancer. J Clin Invest. (2014) 124:3901-12. doi: 10.1172/JCI73777

62. Timoshenko AV, Chakraborty C, Wagner GF, Lala PK. COX-2-mediated stimulation of the lymphangiogenic factor VEGF-C in human breast cancer. Br J Cancer. (2006) 94:1154-63. doi: 10.1038/sj.bjc.6603067

63. Soumaoro LT, Uetake H, Takagi Y, Iida S, Higuchi T, Yasuno M, et al. Coexpression of VEGF-C and Cox-2 in human colorectal cancer and its association with lymph node metastasis. Dis Colon Rectum. (2006) 49:392-8. doi: $10.1007 /$ s10350-005-0247-x

64. Giovannucci E. The prevention of colorectal cancer by aspirin use. Biomed Pharmacother. (1999) 53:303-8. doi: 10.1016/S0753-3322(00)88500-5

65. Rothwell PM, Fowkes FG, Belch JF, Ogawa H, Warlow CP, Meade TW. Effect of daily aspirin on long-term risk of death due to cancer: analysis of individual patient data from randomised trials. Lancet. (2011) 377:31-41. doi: 10.1016/S0140-6736(10)62110-1

66. Rothwell PM, Wilson M, Price JF, Belch JF, Meade TW, Mehta Z. Effect of daily aspirin on risk of cancer metastasis: a study of incident cancers during randomised controlled trials. Lancet. (2012) 379:1591-601. doi: 10.1016/S0140-6736(12)60209-8

67. Karnezis T, Shayan R, Caesar C, Roufail S, Harris NC, Ardipradja K, et al. VEGF-D promotes tumor metastasis by regulating prostaglandins produced by the collecting lymphatic endothelium. Cancer Cell. (2012) 21:181-95. doi: 10.1016/j.ccr.2011.12.026

68. Kubo H, Hosono K, Suzuki T, Ogawa Y, Kato H, Kamata H, et al. Host prostaglandin EP3 receptor signaling relevant to tumorassociated lymphangiogenesis. Biomed Pharmacother. (2010) 64:101-6. doi: 10.1016/j.biopha.2009.04.039

69. Ji H, Cao R, Yang Y, Zhang Y, Iwamoto H, Lim S, et al. TNFR1 mediates TNF-alpha-induced tumour lymphangiogenesis and metastasis by modulating VEGF-C-VEGFR3 signalling. Nat Commun. (2014) 5:4944. doi: 10.1038/ncomms5944

70. Cao R, Ji H, Feng N, Zhang Y, Yang X, Andersson P, et al. Collaborative interplay between FGF-2 and VEGF-C promotes lymphangiogenesis and metastasis. Proc Natl Acad Sci USA. (2012) 109:15894-9. doi: 10.1073/pnas.1208324109

71. Cao R, Bjorndahl MA, Religa P, Clasper S, Garvin S, Galter D, et al. PDGF-BB induces intratumoral lymphangiogenesis and promotes lymphatic metastasis. Cancer Cell. (2004) 6:333-45. doi: 10.1016/j.ccr.2004.08.034

72. Fagiani E, Lorentz P, Kopfstein L, Christofori G. Angiopoietin1 and-2 exert antagonistic functions in tumor angiogenesis, yet both induce lymphangiogenesis. Cancer Res. (2011) 71:5717-27. doi: 10.1158/0008-5472.CAN-10-4635

73. Gore J, Imasuen-Williams IE, Conteh AM, Craven KE, Cheng M, Korc M. Combined targeting of TGF-beta, EGFR and HER2 suppresses lymphangiogenesis and metastasis in a pancreatic cancer model. Cancer Lett. (2016) 379:143-53. doi: 10.1016/j.canlet.201 6.05.037

74. Liu D, Li L, Zhang XX, Wan DY, Xi BX, Hu Z, et al. SIX1 promotes tumor lymphangiogenesis by coordinating TGFbeta signals that increase expression of VEGF-C. Cancer Res. (2014) 74:5597-607. doi: 10.1158/0008-5472.CAN-13-3598

75. Oka M, Iwata C, Suzuki HI, Kiyono K, Morishita Y, Watabe T, et al. Inhibition of endogenous TGF-beta signaling enhances lymphangiogenesis. Blood. (2008) 111:4571-9. doi: 10.1182/blood-2007-10-120337

76. Harrell MI, Iritani BM, Ruddell A. Tumor-induced sentinel lymph node lymphangiogenesis and increased lymph flow precede melanoma metastasis. Am J Pathol. (2007) 170:774-86. doi: 10.2353/ajpath.2007.060761

77. Hirakawa S, Kodama S, Kunstfeld R, Kajiya K, Brown LF, Detmar M. VEGF-A induces tumor and sentinel lymph node lymphangiogenesis and promotes lymphatic metastasis. J Exp Med. (2005) 201:1089-99. doi: 10.1084/jem.20041896

78. Qian CN, Berghuis B, Tsarfaty G, Bruch M, Kort EJ, Ditlev J, et al. Preparing the "soil": the primary tumor induces vasculature reorganization in the sentinel lymph node before the arrival of metastatic cancer cells. Cancer Res. (2006) 66:10365-76. doi: 10.1158/0008-5472.CAN-06-2977

79. Kim M, Koh YJ, Kim KE, Koh BI, Nam DH, Alitalo K, et al. CXCR4 signaling regulates metastasis of chemoresistant melanoma cells by a lymphatic metastatic niche. Cancer Res. (2010) 70:10411-21. doi: 10.1158/0008-5472.CAN-10-2591

80. Issa A, Le TX, Shoushtari AN, Shields JD, Swartz MA. Vascular endothelial growth factor-C and $\mathrm{C}-\mathrm{C}$ chemokine receptor 7 in tumor cell-lymphatic cross-talk promote invasive phenotype. Cancer Res. (2009) 69:349-57. doi: 10.1158/0008-5472.CAN-08-1875

81. Garmy-Susini B, Avraamides CJ, Schmid MC, Foubert P, Ellies LG, Barnes L, et al. Integrin alpha4betal signaling is required for lymphangiogenesis and tumor metastasis. Cancer Res. (2010) 70:3042-51. doi: 10.1158/0008-5472.CAN-09-3761

82. Garmy-Susini B, Avraamides CJ, Desgrosellier JS, Schmid MC, Foubert P, Ellies LG, et al. PI3Kalpha activates integrin alpha4betal to establish a metastatic niche in lymph nodes. Proc Natl Acad Sci USA. (2013) 110:9042-7. doi: 10.1073/pnas.1219603110

83. Irshad S, Flores-Borja F, Lawler K, Monypenny J, Evans R, Male $\mathrm{V}$, et al. RORgammat $(+)$ innate lymphoid cells promote lymph node metastasis of breast cancers. Cancer Res. (2017) 77:1083-96. doi: 10.1158/0008-5472.CAN-16-0598

84. Miteva DO, Rutkowski JM, Dixon JB, Kilarski W, Shields JD, Swartz MA. Transmural flow modulates cell and fluid transport functions of lymphatic endothelium. Circ Res. (2010) 106:920-31. doi: 10.1161/CIRCRESAHA.109.207274

85. Shields JD, Fleury ME, Yong C, Tomei AA, Randolph GJ, Swartz MA. Autologous chemotaxis as a mechanism of tumor cell homing to lymphatics via interstitial flow and autocrine CCR7 signaling. Cancer Cell. (2007) 11:526-38. doi: 10.1016/j.ccr.2007.04.020

86. Gunther K, Leier J, Henning G, Dimmler A, Weissbach R, Hohenberger $\mathrm{W}$, et al. Prediction of lymph node metastasis in colorectal carcinoma by expressionof chemokine receptor CCR7. Int J Cancer. (2005) 116:726-33. doi: $10.1002 /$ ijc. 21123

87. Cabioglu N, Yazici MS, Arun B, Broglio KR, Hortobagyi GN, Price JE, et al. CCR7 and CXCR4 as novel biomarkers predicting axillary lymph node metastasis in T1 breast cancer. Clin Cancer Res. (2005) 11:5686-93. doi: 10.1158/1078-0432.CCR-05-0014 
88. Mashino K, Sadanaga N, Yamaguchi H, Tanaka F, Ohta M, Shibuta K, et al. Expression of chemokine receptor CCR7 is associated with lymph node metastasis of gastric carcinoma. Cancer Res. (2002) 62:2937-41.

89. Das S, Sarrou E, Podgrabinska S, Cassella M, Mungamuri SK, Feirt N, et al. Tumor cell entry into the lymph node is controlled by CCL1 chemokine expressed by lymph node lymphatic sinuses. J Exp Med. (2013) 210:1509-28. doi: 10.1084/jem.20111627

90. van der Weyden L, Arends MJ, Campbell AD, Bald T, Wardle-Jones $\mathrm{H}$, Griggs $\mathrm{N}$, et al. Genome-wide in vivo screen identifies novel host regulators of metastatic colonization. Nature. (2017) 541:233-6. doi: 10.1038/nature20792

91. Black SA, Nelson AC, Gurule NJ, Futscher BW, Lyons TR. Semaphorin 7a exerts pleiotropic effects to promote breast tumor progression. Oncogene. (2016) 35:5170-8. doi: 10.1038/onc.2016.49

92. Elder AM, Tamburini BAJ, Crump LS, Black SA, Wessells VM, Schedin PJ, et al. Semaphorin 7A promotes macrophage-mediated lymphatic remodeling during postpartum mammary gland involution and in breast cancer. Cancer Res. (2018) 78:6473-85. doi: 10.1158/0008-5472.CAN-18-1642

93. Swartz MA, Lund AW. Lymphatic and interstitial flow in the tumour microenvironment: linking mechanobiology with immunity. Nature reviews. Cancer. (2012) 12:210-9. doi: 10.1038/nrc3186

94. Kimura T, Sugaya M, Oka T, Blauvelt A, Okochi H, Sato S. Lymphatic dysfunction attenuates tumor immunity through impaired antigen presentation. Oncotarget. (2015) 6:18081-93. doi: 10.18632/oncotarget.4018

95. Galon J, Costes A, Sanchez-Cabo F, Kirilovsky A, Mlecnik B, LagorcePages C, et al. Type, density, and location of immune cells within human colorectal tumors predict clinical outcome. Science. (2006) 313:1960-4. doi: 10.1126/science.1129139

96. Fridman WH, Pages F, Sautes-Fridman C, Galon J. The immune contexture in human tumours: impact on clinical outcome. Nature reviews. Cancer. (2012) 12:298-306. doi: 10.1038/nrc3245

97. Peske JD, Thompson ED, Gemta L, Baylis RA, Fu YX, Engelhard VH. Effector lymphocyte-induced lymph node-like vasculature enables naive T-cell entry into tumours and enhanced anti-tumour immunity. Nat Commun. (2015) 6:7114. doi: 10.1038/ncomms8114

98. Thompson ED, Enriquez HL, Fu YX, Engelhard VH. Tumor masses support naive $\mathrm{T}$ cell infiltration, activation, and differentiation into effectors. $J$ Exp Med. (2010) 207:1791-804. doi: 10.1084/jem.20092454

99. Yu P, Lee Y, Liu W, Chin RK, Wang J, Wang Y, et al. Priming of naive T cells inside tumors leads to eradication of established tumors. Nat Immunol. (2004) 5:141-9. doi: 10.1038/ni1029
100. Roberts EW, Broz ML, Binnewies M, Headley MB, Nelson AE, Wolf $\mathrm{DM}$, et al. Critical role for CD103(+)/CD141(+) dendritic cells bearing CCR7 for tumor antigen trafficking and priming of $\mathrm{T}$ cell immunity in melanoma. Cancer Cell. (2016) 30:324-36. doi: 10.1016/j.ccell.201 6.06 .003

101. Russo E, Teijeira A, Vaahtomeri K, Willrodt AH, Bloch JS, Nitschke $\mathrm{M}$, et al. Intralymphatic CCL21 promotes tissue egress of dendritic cells through afferent lymphatic vessels. Cell Rep. (2016) 14:1723-34. doi: 10.1016/j.celrep.2016.01.048

102. Teijeira A, Rouzaut A, Melero I. Initial afferent lymphatic vessels controlling outbound leukocyte traffic from skin to lymph nodes. Front Immunol. (2013) 4:433. doi: 10.3389/fimmu.2013.00433

103. Acton SE, Astarita JL, Malhotra D, Lukacs-Kornek V, Franz B, Hess PR, et al. Podoplanin-rich stromal networks induce dendritic cell motility via activation of the C-type lectin receptor CLEC-2. Immunity. (2012) 37:27689. doi: 10.1016/j.immuni.2012.05.022

104. Bordry N, Broggi MAS, de Jonge K, Schaeuble K, Gannon PO, Foukas PG, et al. Lymphatic vessel density is associated with CD8(+) T cell infiltration and immunosuppressive factors in human melanoma. Oncoimmunology. (2018) 7:e1462878. doi: 10.1080/2162402X.2018.1462878

105. Baitsch L, Baumgaertner P, Devevre E, Raghav SK, Legat A, Barba L, et al. Exhaustion of tumor-specific CD8(+) T cells in metastases from melanoma patients. J Clin Invest. (2011) 121:2350-60. doi: 10.1172/JCI46102

106. Shields JD, Kourtis IC, Tomei AA, Roberts JM, Swartz MA. Induction of lymphoidlike stroma and immune escape by tumors that express the chemokine CCL21. Science. (2010) 328:749-52. doi: 10.1126/science.1185837

107. Riedel A, Shorthouse D, Haas L, Hall BA, Shields J. Tumor-induced stromal reprogramming drives lymph node transformation. Nat Immunol. (2016) 17:1118-27. doi: $10.1038 /$ ni.3492

Conflict of Interest Statement: The authors declare that the research was conducted in the absence of any commercial or financial relationships that could be construed as a potential conflict of interest.

Copyright (c) 2019 Garnier, Gkountidi and Hugues. This is an open-access article distributed under the terms of the Creative Commons Attribution License (CC BY). The use, distribution or reproduction in other forums is permitted, provided the original author(s) and the copyright owner(s) are credited and that the original publication in this journal is cited, in accordance with accepted academic practice. No use, distribution or reproduction is permitted which does not comply with these terms. 